\title{
Post-Surgical TMJ Ankylosis followed by Orthodontic Correction of Class II Div-1 Malocclusion: A Case Report
}

\author{
Hossain MZ ${ }^{1}$ BDS, PhD, Ali $\mathrm{S}^{2}$ BDS, Hasan $\mathrm{MM}^{3}$ BDS, FCPS and Zakir $\mathrm{S}^{4}$ BDS
}

\begin{abstract}
This case report describe the management of a 17 years old female patient having class II div 1 malocclusion with history of temporomandibular joint surgery. Intraoral examination revealed that patient have proclined maxillary incisors, exaggerated lower curve of spee, and moderate crowding in upper and lower jaw. Other complaints are bite problem, inability to grinding food and unaesthetic smile. After extraction of upper 1st premolars, canine retraction was done which was followed by retraction of severely proclined upper anterior teeth by third order bend in rectangular stainless steel arch wire. For anchorage management TPA, intra oral anchorage with tip back \& toe in bends in stainless steel arch wire was satisfactory. Following treatment, marked improvement in patient's smile, facial profile and lip competence were achieved and there was a remarkable increase in the patient's confidence and quality of life.
\end{abstract}

Key words: TMJ ankylosis, post-surgical orthodontic treatment.

\section{INTRODUCTION}

Class II div 1 malocclusion is more prevalent than any type of malocclusion after Class I malocclusion in our country. ${ }^{1,2}$ Over the last decade, increasing numbers of adults have become aware of orthodontic treatment and are demanding high quality treatment, in the shortest possible time with increased efficiency and reduced costs. ${ }^{3}$ Class II malocclusions can be treated by several means, according to the characteristics associated with the problem, such as antero-posterior discrepancy, age, and patient compliance. ${ }^{4}$ Methods include extra-oral appliances, functional appliances and fixed appliances associated with Class II inter-maxillary elastics. ${ }^{5}$ On the other hand, correction of Class II malocclusions in non-growing patients usually includes orthognathic surgery or selective removal of permanent teeth, with subsequent dental camouflage to mask the skeletal discrepancy. The indications for extractions in orthodontic practice have historically been controversial. ${ }^{6-8}$ Premolars are probably the most commonly extracted teeth for orthodontic purposes as they are conveniently located between the anterior and posterior segments. Variations in extraction sequences including upper and lower first or second premolars have been recommended by different authors for a variety of reasons. ${ }^{9-14}$

For correction of Class II malocclusions in non-growing patients extractions can involve maxillary premolars or 2 maxillary and 2 mandibular premolars. ${ }^{15-16}$ It is usually not the skeletal characteristics of a Class II malocclusion that primarily determine whether it should be treated with 2 or 4 premolar extractions but, rather, the dentoalveolar characteristics. The extraction of only 2 maxillary premolars is generally indicated when there is no crowding or cephalometric discrepancy in the mandibular arch. ${ }^{17-18}$

Extraction of 4 premolars is indicated primarily for crowding in the mandibular arch, a cephalometric discrepancy, or a combination of both, in growing patients. ${ }^{17-19}$

Recent studies have shown that patient satisfaction with camouflage treatment is similar to that achieved with surgical mandibular advancement ${ }^{20}$ and that treatment with two maxillary premolar extractions gives a better occlusal result than treatment with four premolars extractions. ${ }^{2}$

\section{PRETREATMENT ASSESSMENT}

A 17 year old female reported to the Orthodontic Department at Dhaka Dental College \& Hospital with multiple complaints- "I am unable to bite properly", "I am unable to close my lips". She gave a history of previous TMJ surgery for ankylosis. Extra oral examination revealed a mesocephalic asymmetrical face, covex profile and recessive chin. Intra oral examination revealed that the patient had a full Class II molar and canine relationship, excessively proclined maxillary incisors with an overjet of $11 \mathrm{~mm}$. Cephalometric examination revealed Class II skeletal relation with severe maxillary incisor proclination with horizontal growth pattern. Although the sagittal jaw discrepancy was severe, the selective extraction of two permanent maxillary first premolar teeth were considered.

1 Prof. Dr. Md. Zakir Hossain, Professor and Head, Department of Orthodontics and Dentofacial Orthopedics, Dhaka Dental College, ${ }^{2}$ Dr. Md. Sher Ali BDS, FCPS Trainee, Dept. of Orthodontics \& Dentofacial Orthopedics, Dhaka Dental College, ${ }^{3}$ Dr. Md. Mahdi Hasan BDS, FCPS Trainee, Dept. of Orthodontics \& Dentofacial Orthopedics, Dhaka Dental College and ${ }^{4}$ Dr. Shehreen Zakir BDS, Intern Doctor, Bangladesh Dental College 
Our treatment objective focused on the chief complaint of the patient, and the treatment plan was based on the specific treatment goals for this individual.

\section{DIAGNOSIS}

Skeletal Class II division 1 malocclusion with severe proclination of maxillary incisors, convex profile, steep mandibular plane angle, incompetent lips, increased overjet.

\section{TREATMENT OBJECTIVES}

1. Achieve occlusal intercuspation with a Class I canine relationship.

2. Establishment of an ideal overjet \& overbite.

3. Correct the antero-posterior dental relationship.

4. Correction of deep overbite.

5. Upper arch contraction.

6. Final settling of the occlusion and arch coordination.
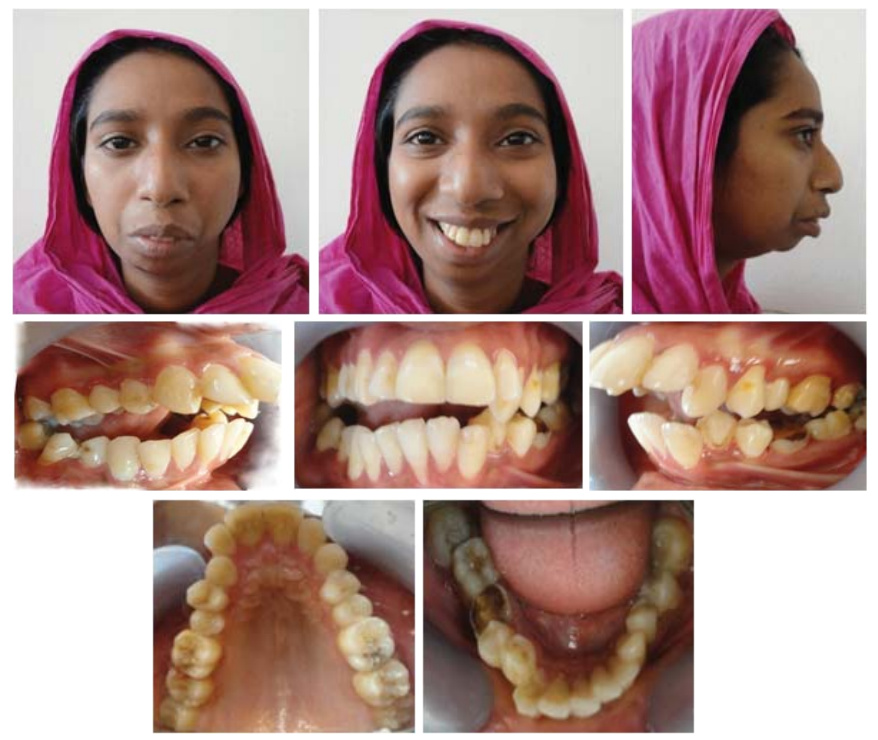

Fig1. Pre-treatment extra-oral \& intra-oral photographs

\section{TREATMENT PROGRESS}

The maxillary first premolars were extracted. The first molars were banded and the maxillary and mandibular teeth were bonded from 2nd premolar to 2nd premolar with a 0.018 slot standard edge wise brackets. Retractions of upper canines was done in 0.016 inch round stainless steel arch wire with stop loops and tip back and toe-in anchorage bends.
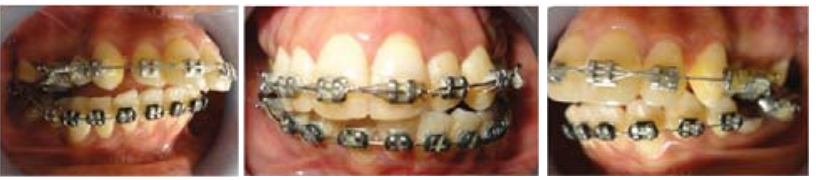

Fig 2: Intra-oral photograph during treatment

Arch contraction and closure of extraction spaces in upper arch was done by rectangular ( 0.017 X 0.025 inch) Stainless Steel arch wire with proper control of third order bend 'Torque'. Final settling of occlusion was done with proper interdigitation, inclination, angulation, ideal overjet and overbite. Debonding and retention was given by upper modified Hawley's retainer\& lower Hawley's retainer. Patient was advised to come for follow up in retention period.

\section{POST TREATMENT ASSESSMENT:}

Lip competence and a straight profile were achieved, improving the patient's facial appearance. A functional occlusion with normal overjet and overbite; Class I canine relationship was achieved. Duration of the treatment was 30 months. The patient and her parent were very happy with complete satisfaction. Improvement can be seen from the pre and post treatment extra-oral and intra-oral photographs (fig: 1 \& 3) and pre and post treatment cephalometric analysis. (Fig: 4 and table 1)

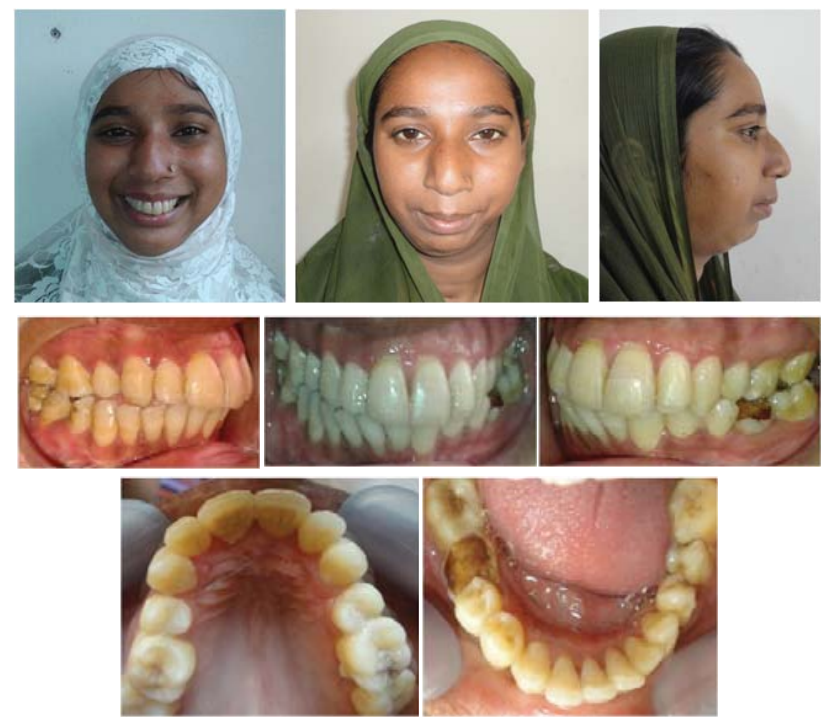

Fig 3: Post treatment extra-oral \& intra-oral photograph. 

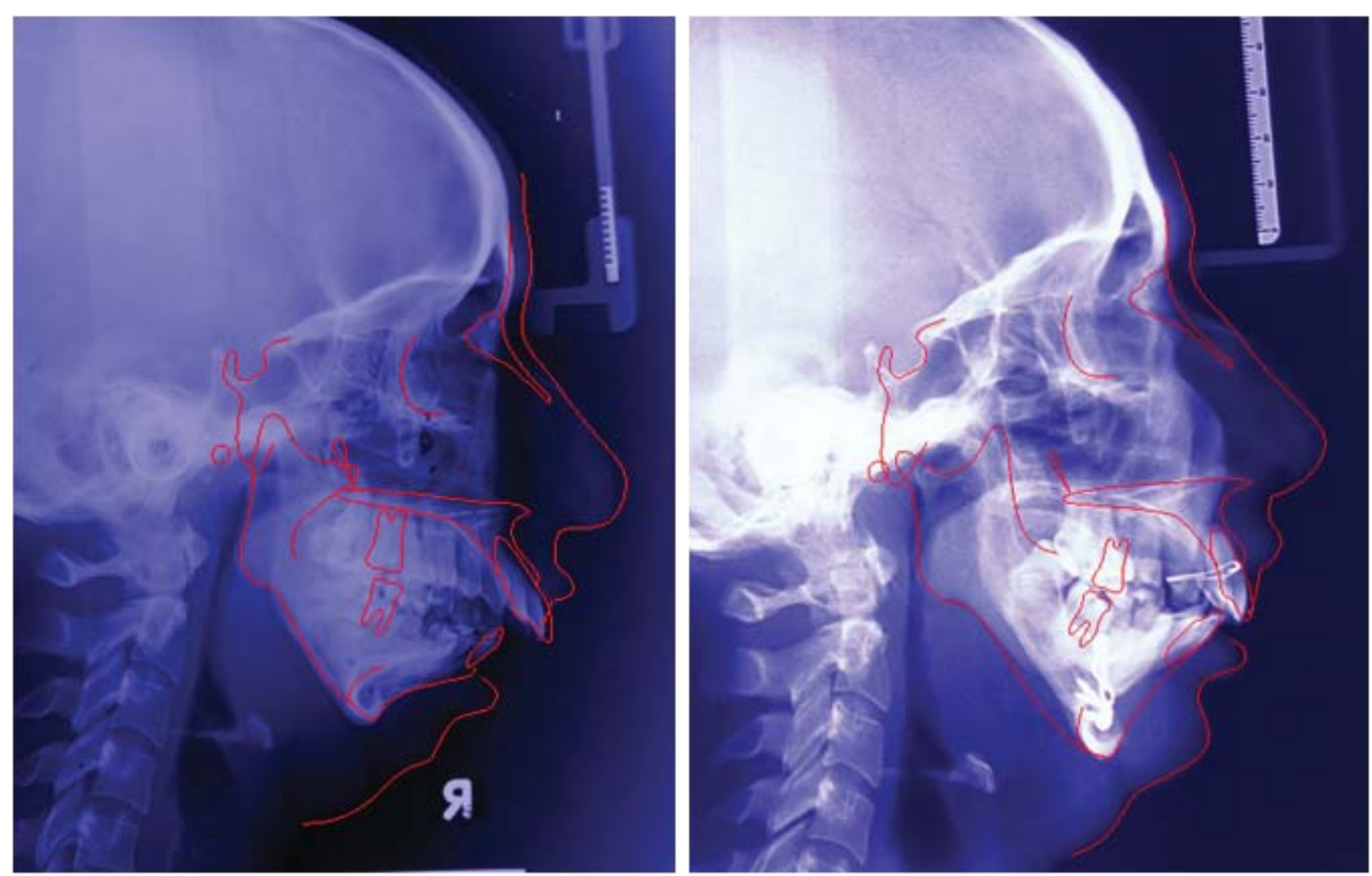

Fig 4: Pre \& post treatment cephalometry tracing.

Table: 1 - Pre \& post treatment Lateral Cephalogram: Steiner's analysis

\begin{tabular}{|c|c|c|c|}
\hline Parameters & $\begin{array}{l}\text { Reference value } \\
\text { (Bangladeshi) }\end{array}$ & $\begin{array}{l}\text { Pt's measurement } \\
\text { Pre-treatment }\end{array}$ & $\begin{array}{l}\text { Pt's } \\
\text { measurement } \\
\text { post-treatment }\end{array}$ \\
\hline $\mathrm{SNA}^{\circ}$ & $83.8^{\circ}$ & $81.9^{\circ}$ & $82.2^{\circ}$ \\
\hline $\mathrm{SNB}^{\circ}$ & $81.5^{\circ}$ & $68.9^{\circ}$ & $73.2^{\circ}$ \\
\hline $\mathrm{ANB}^{\circ}$ & $2.3^{\circ}$ & 13 & $9^{0}$ \\
\hline$\| A^{\circ}$ & $117.7^{\circ}$ & 112.9 & $115.1^{0}$ \\
\hline $\mathrm{MPA}^{\circ}$ & $25.8^{\circ}$ & $61.5^{\circ}$ & $51^{0}$ \\
\hline U1 to $\mathrm{NA}^{\circ}$ & $29.8^{\circ}$ & $11.9^{\circ}$ & $23.7^{\circ}$ \\
\hline $\mathrm{U} 1$ to $\mathrm{NA} \mathrm{mm}$ & $8 \mathrm{~mm}$ & $3 \mathrm{~mm}$ & $1 \mathrm{~mm}$ \\
\hline $\mathrm{L} 1$ to $\mathrm{NB}^{\circ}$ & $30.6^{\circ}$ & $12.5^{\circ}$ & $30.5^{0}$ \\
\hline $\mathrm{L} 1$ to $\mathrm{NB} \mathrm{mm}$ & $8 \mathrm{~mm}$ & $3 \mathrm{~mm}$ & $4 \mathrm{~mm}$ \\
\hline
\end{tabular}




\section{DISCUSSION}

Patient had improved smile and profile after orthodontic treatment. Upper incisors were retracted to achieve normal incisor inclinations, overjet and overbite. Bilateral Class I canine relation was achieved with maximum intercuspation. The case was successfully managed by contemporary orthodontic technique with intra oral anchorage incorporated in arch wire that restored functional and aesthetic demand of the patient.

\section{CONCLUSIONS}

Camouflage treatment of Class II malocclusion in adults is challenging. Extractions of premolars if undertaken after a thorough diagnosis leads to positive profile changes and an overall satisfactory facial aesthetics. A well-chosen individualized treatment plan, undertaken with sound biomechanical principles and appropriate control of orthodontic mechanics to execute the plan is the surest way to achieve predictable results with minimal side effects.

\section{REFERENCES.}

1. Hossain MZ et al. Management of Class II Div 1 Malocclusion: cephalometric \& clinical evaluation: Bangladesh Dental Journal, 2005; Vol 21 No.1 2

2. Hossain MZ Orthodontic management of class II Div 1 malocclu-sion- A case report: Journal of Oral Health , 1995; Vol:2 No: 1

3. Hossain MZ et al, Prevalence of malocclusion and treatment facilities at Dhaka Dental College and Hospital. Journal of Oral Health, vol: 1, No. 1, 1994

4. Ahmed $\mathrm{N}$ et al, Prevalence of malocclusion and its aetiological factors. Journal of Oral Health, Vol. 2 No. 2 April 1996

5. Khan RS, Horrocks EN. A study of adult orthodontic patients and their treatment. Br J Orthod,18(3):183-194; 1991.

6. Salzmann JA. Practice of orthodontics. Philadelphia: J. B. Lippincott Company; p. 701-24; 1966.
7. McNamara, J.A.: Components of Class II malocclusion in children 8- 10 years of age, Angle Orthod, 51:177-202; 1981.

8. Case C S. The question of extraction in orthodontia. American Journal of Orthodontics, 50: 660-691; 1964.

9. Case C S. The extraction debate of 1911 by Case, Dewey, and Cryer. Discussion of Case: the question of extraction in orthodontia. American Journal of Orthodontics, 50: 900-912; 1964.

10. Tweed C. Indications for the extraction of teeth in orthodontic procedure. American Journal of Orthodontics 30: 405-428; 1944.

11. Staggers J A. A comparison of results of second molar and first premolar extraction treatment. American Journal of Orthodontics and Dentofacial Orthopedics, 98: 430-36; 1990.

12. Luecke P E, Johnston L E. The effect of maxillary first premolar extraction and incisor retraction on mandibular position: testing the central dogma of 'functional orthodontics'. American Journal of Orthodontics and Dentofacial Orthopedics, 101: 4-12; 1992.

13. Proffit W R, Phillips C, Douvartzidis N. A comparison of outcomes of orthodontic and surgical-orthodontic treatment of Class II malocclusion in adults. American Journal of Orthodontics and Dentofacial Orthopedics, 101: 556-565; 1992.

14. Paquette D E, Beattie J R, Johnston L E. A long-term comparison of non extraction and premolar extraction edgewise therapy in 'borderline' Class II patients. American Journal of Orthodontics and Dento-facial Orthopedics, 102:1-14; 1992.

15. Taner-Sarısoy L, Darendeliler N. The influence of extraction treatment on craniofacial structures: evaluation according to two different factors. American Journal of Orthodontics and Dento-facial Orthopedics 115: 508-514; 1999.

16. Basciftci F A, Usumez S. Effects of extraction and non extraction treatment on Class I and Class II subjects, Angle Orthodontist 73:36-42; 2003.

17. Cleall JF, Begole EA. Diagnosis and treatment of Class II Division 2 malocclusion. Angle Orthod 52:38-60; 1982.

18. Strang RHW. Tratado de ortodoncia. Buenos Aires: Editorial Bibliogra fica Argentina; 1957. p. 560-70, 657-71.

19. Bishara SE, Cummins DM, Jakobsen JR, Zaher AR. Dentofacial and soft tissue changes in Class II, Division 1 cases treated with and without extractions. Am J Orthod Dentofacial Orthop 107:28-37;1995.

20. Rock WP. Treatment of Class II malocclusions with removable appliances. Part 4. Class II Division 2 treatment. Br Dent J 168:298-302;1990.
Dr. Md. Sher Ali BDS, FCPS Trainee

Dept. of Orthodontics \& Dentofacial Orthopedics

Dhaka Dental College

Cell: +8801711142254

E-mail: dr.sherali@yahoo.com 